\title{
AC 2007-1775: DIGITAL DESIGN, BIM, AND DIGITAL FABRICATION: UTILIZATION AND INTEGRATION IN ARCHITECTURAL ENGINEERING CURRICULUMS
}

\section{Stan Guidera, Bowling Green State University}

DR. STAN GUIDERA is an Associate Professor of Architecture in the

Architectural/Environmental Design Studies Program in the College of Technology at Bowling Green State University. He teaches design studios, advanced CAD courses and computer rendering and animation. He is a registered architect and has used computer-aided design extensively in professional practice. 


\title{
Digital Design, BIM, and Digital Fabrication: Utilization and Integration in Architectural Engineering Curriculums
}

\begin{abstract}
This paper presents the findings of a study conducted to investigate both current and potential roles of computer modeling, design visualization, building information modeling, and digital fabrication in architectural engineering curriculums. Data was collected to document the current status of the utilization of architectural CAD applications in architectural engineering programs and to identify curricular areas faculty perceive as having potential for additional integration of digital media. Additionally, the paper documented the extent to which architectural engineering faculty perceived computer modeling, building information modeling, and digital fabrication skills are relevant to the professional preparation of students and the extent to which this perception correlates with other factors and variables. The findings suggested that while digital design tools were utilized over a broad range of curricular areas faculty responding to this survey did not place a high priority on skill development with BIM and that there was a very limited priority placed on course content related to fabrication.
\end{abstract}

\section{Introduction}

Digital tools have taken on a central role in the architectural design and document production process as applications utilizing object oriented programming have facilitated a shift from the role of computation as a 2D documentation tool to a 3D design tool. Object oriented programming is computational ontology; a data model that represents a "domain" and is used to reason about the objects in that domain and the relations between them. Programmers define a data structure, and then define the operations that can be applied to that data structure. Therefore, the data structure is defined as an object that includes both data and functions with specified relationships between the object and other objects [1]. Consequently, architectural objects relate "intelligently" [2] and function more intuitively, enabling powerful applications to be easier and more intuitive to use. Parametric object-based design tools have become standard in architectural CAD applications and the ability to utilize parametric control of geometry and dimensional relationships has become an expectation among practitioners [3].

Many prominent architectural practices are exploiting advances in digital design technologies as a tool to conceptualize and ultimately construct complex form that, until only recently, would have been difficult to develop and largely unfeasible if not impossible to engineer and construct. ARUP and Partners use of computer modeling to translate the concept for the Sydney Opera house (Figure 1) into a physical reality is an example of a pioneering effort in utilizing digital design tools [4]. More recently, Frank Gehry's extensive utilization of computer modeling has received considerable attention and has been documented in some detail [4]. His highly recognizable work, characterized by sculptural compositions of curving steel surfaces, is a product largely dependent upon computation. It has been argued that his critically acclaimed Guggenheim Bilboa in Barcelona, Spain (Figure 2), would have been impossible to design, engineer, and construct without computer modeling and that "computer tools were absolutely imperative for the execution of the building's design" [5]. 
The more recent evolution of Building Information Modelers will potentially have farreaching implications for the vast majority of architectural practices in terms of both design process and project delivery. Building Information Modeling (BIM), utilizes a model-centric approach where the computer model functions as a central graphical and information interdisciplinary repository which, when optimized, facilitates design collaboration and coordination among the project designers, clients, and construction teams. Additionally, the parametric and object-oriented modeling technologies underlying BIM applications also facilitate digital fabrication of both prototypes and manufactured components. It has been proposed that building information modeling delivers technology that actually meets the expectations of the profession that have previously gone un-fulfilled, and that BIM can "finally harness the power of computers in a real value-added design process that doesn't just mimic drafting." [6]. According to Roberts, "the growing adoption of the building information modeling (BIM) methodology has raised practitioners' expectations and overall awareness of the value of tools and technologies that offer more informed design experiences." [6]

The implications of building information modeling for architectural design is evident in recent developments regarding requirements for future architectural services commissioned by the United States General Services, a government agency which is the country's largest procurer of construction services [7]. The GSA's Office of Chief Architect (OCA) has mandated that beginning in 2007, architects will be required to utilize Building Information Modeling (BIM) programs in early concept design. This mandate will require all disciplines involved in project delivery, including engineers, consultants, and contractors, to utilize BIM. However, it should be noted that the GSA makes a distinction between 3D modeling and Building Information Modeling. The GSA stated that "while 3D models make valuable contributions to communications, not all 3D models qualify as BIM models since a 3D geometric representation is only part of the BIM concept," and added that "critical to successful integration of computer models into project coordination, simulation, and optimization is the inclusion of information" [8]. The mandate is expected to benefit project delivery by improving decision-making processes, and improve interoperability and efficiency by creating an industry neutral standard for construction projects [7]. The GSA is also considering the potential of building information modeling beyond initial design and construction as the organization has launched programs and initiatives encouraging the use of BIM technology for spatial program validation, 4D phasing, laser scanning, energy and sustainability, and circulation design validation [8].

While the implications of BIM for the AEC professions are far-reaching, there are implications for current as well as potential uses of digital design tools in architectural education. The adoption of CAD, computer modeling, and computer rendering and visualization tools has increased dramatically in architectural education. However, with adoption of BIM applications in professional practices, including even smaller firms which would not typically have resources to adopt advanced technologies [9], it could be anticipated that, for architectural graduates, previous employment criteria such as proficiency with computer aided drafting will be supplanted by expectations that graduates will be proficient with $3 \mathrm{D}$ computing skills and possess skills related to building information modeling. However, as object-oriented programming and parametric modeling that provide the core for functionality BIM applications, 3D modeling is easier to learn and use when utilizing a BIM application [2]. While important in professional contexts, in educational environments ease of use is a necessary attribute for the 
effective application of digital design tools in education given the limited experience with computer modeling among most students. Most importantly, these characteristics make it conceivable that building information modelers may have implications for the adoption of digital design and representation tools in other curricular areas.

A review of the curriculums of architecture schools indicates that nearly all architecture and architectural engineering undergraduate degree offerings include course offerings related to computer aided design applications. What is not evident is what specific applications are being most commonly utilized, the extent to which these applications are utilized in the curriculum beyond those specific courses, and the extent to which programs are including content on, building information modeling. As a result, a research study was conducted to collect data related to the use of these technologies in curriculums. More specifically, the study focused on architectural engineering curriculums based on two assumptions. First, it is assumed that architectural engineering education emphasizes an integration of both engineering and architectural design content, a position supported by review of many AE programs. Second, it is assumed that industry developments such as the GSA mandate will require all disciplines involved in design and construction to utilize advanced computing technologies organized around a model-centric design process involving a greater degree of collaboration than was needed in the past. Therefore, architectural engineering faculty may be positioned to provide insight into the multi-disciplinary utilization of model-centric computing applications in academics.

The data collected was used to document the specific software used in architectural engineering programs and documented the current utilization of digital design technologies in three general areas: Computer Aided Drafting (two dimensional CAD), Computer Aided Design and modeling (three dimensional CAD), design visualization (computer rendering, animation, and representation), and building information modeling (BIM). In addition to collecting data related to the use of these technologies in specific curricular areas, data was also collected in order to document the curricular areas architectural engineering faculty perceived as having potential for the use of digital design applications. Additionally, the data documented the extent to which architectural engineering faculty perceive $\mathrm{CAD}$, computer aided design (3D computer modeling), and design visualization (rendering, animation, and visualization) skills are relevant to the professional preparation of students and the extent to which this perception correlated with instructional focus and the number of students enrolled in architectural engineering. Computer aided drafting, 3D computer modeling, and design visualization were identified for investigation based on three premises. First, it can be argued that there is an increasing use of these technologies in practice and education. Secondly, 2D, 3D, and visualization operations can be used as a sub-set of building information modelers and can be utilized independently of more advanced BIM features [10]. Third, successful implementation of BIM in professional practice often requires building information modeling to "co-exist with 2D drafting or 3D modeling applications already in use" [11].

\section{Methodology}

The study population was composed of all full-time faculty in ABET accredited 4-year and graduate level architectural engineering programs. The ABET web site was used to identify 
the 23 institutions listed by ABET as having programs that met the study criteria [12]. Potential participants and their e-mail addresses were identified from faculty lists on departmental and college web pages and also from searches on university web sites. The names and e-mail addresses were complied in an excel spreadsheet for use in distributing the survey. It should be noted that one institution requested that their faculty not be invited to participate in the study.

The study was structured to address research questions related to the type of digital design applications being utilized in architectural engineering programs and also to identify current as well as potential uses of Computer Aided Drafting (2D CAD), Computer Aided Design and Modeling (3D CAD), and design visualization (computer rendering, animation, and representation) in architectural engineering curriculums. These research questions were:

1. What specific digital design computer applications are being utilized in AE curriculums?

2. What is the extent to which the standard content areas in most architectural engineering curriculums are currently utilizing Computer Aided Drafting (2 dimensional CAD), Computer Aided Design and modeling (3 dimensional CAD), and design visualization (computer rendering, animation, and representation)?

The study was also structured to address specific research questions related to current utilization of building information modeling applications, including the relationship between the use of building information modeling and Computer Aided Design (3D computer modeling) and design visualization (computer rendering, animation, and representation) in architectural engineering curriculums. These research questions were:

3. Of the six GSA approved Building Information Modeling software applications, which are the most commonly used in AE curriculums?

4. What Building Information Modeling features are utilized in AE curriculums

5. To what extent do AE faculty perceive that content related to Building Information Modeling is covered in their AE curriculums?

6. To what extent do AE faculty perceive that content related to skill development with Building Information Modeling should be a priority for student's professional preparation?

7. To what extent do AE faculty perceive that content related to skill development with Computer Aided Drafting (2 dimensional CAD), Computer Aided Design and modeling (3D computer modeling or three-dimensional CAD), and design visualization (computer rendering, animation, and representation) should be made a priority for student's professional preparation?

8. What is the extent to which faculty feel there is potential for standard content areas in most architectural engineering curriculums potential to utilize Computer Aided Drafting (two dimensional CAD), Computer Aided Design and modeling (three dimensional CAD), and design visualization (computer rendering, animation, and representation)?

9. To what extent is computer-aided fabrication used in architectural engineering curriculums? 


\section{Survey Instrument}

A survey instrument was used to collect data related to the research questions. In order to insure that respondents were interpreting terminology used in a similar way, definitions of key terms used were included in the beginning of the survey. The survey definitions provided were as follows:

COMPUTER AIDED DRAFTING refers to the use of computer applications for 2-dimensional documentation, and orthographic drawings.

3D MODELING (computer modeling) refers to the use of computer applications for producing any type of 3D geometry.

COMPUTER AIDED DESIGN refers to the use of computer applications as a 3D design tool for conceptual design and/or design development and/or final design representation.

PARAMETRIC MODELING refers to applications that use techniques such as dimensional constraints, position and size constraints, and alignment relationships to control and manipulate 3D geometry.

OBJECT OR STYLE-BASED MODELING refers to software applications that use pre-defined and customizable object styles to globally manipulate geometry and features such as doors, walls, windows, and assembly components.

The survey included a series of questions designed to collect demographic data from the respondents. These included academic background, faculty rank, instructional experience in architectural engineering, and primary instructional areas. The survey listed six categories for respondents to select from when identifying their academic background. These were complied based on commonly identified academic areas and included Architecture, Architectural Engineering, Engineering: Civil, Engineering: Structural, Engineering: Electrical/Mechanical, and Construction. For faculty who did not feel their academic background was aligned with those listed, a seventh option of "other" was provided. In order to categorize the respondent's primary instructional area, a list was complied of terms that were commonly used in architectural and architectural engineering curriculums. The content area terms used were Architectural History and/or Theory, Structures, Construction and/or building materials and methods, Mechanical/Environmental systems, Civil engineering (site emphasis), Professional practice (contracts, legal, etc.), Architectural Graphics (representation) courses, Architectural Design (design foundations) courses, Architectural Design (upper level and/or graduate design studios), and Computer Aided Drafting and/or Design, and Design Visualization. An option of "other" was also provided. The section also asked respondents to indicate whether they did or did not teach in the architectural engineering curriculum. For respondents that replied "No", the software ended the survey since individuals who did not teach in architectural engineering were not members of the target population. These responses were eliminated from reporting and analysis.

The survey also included two sections that asked the respondents to indicate specific software applications that were used in their architectural engineering curriculums. A list of applications that were most widely used in industry as well as in academic environments was complied, including commonly used CAD applications, non-CAD modeling applications, and applications that were primarily utilized for design visualization. The sections also listed the six 
building information modeling applications approved by the GSA for use in federal projects; ArchiCad (Graphisoft), Autodesk Architectural Desktop (Autodesk, Inc.), Autodesk Revit (Autodesk, Inc.), Bentley Architecture (Bentley Systems, Inc), Catia - Gehry Technologies (Dassault), and Vectorworks (Nemetschek, Inc.) [13]. The first section asked the respondents to identify applications used in the overall curriculum, including classes they did not teach. The second section asked them to identify applications specifically used in their own classes.

The questions related to current and potential use of digital design applications in terms of specific content areas utilized the same content areas used for the primary instructional focus inquiry. However, the content area "Computer Aided Drafting and/or Design" was not included as an option for these questions as it would inherently require use of computer applications. Therefore, the content area terminology used were: Architectural History and/or Theory, Structures, Construction and/or building materials and methods, Mechanical/Environmental systems, Architectural Graphics (representation) courses, Architectural Design (design foundations) courses, and Architectural Design (upper level and/or graduate design studios).

Frequency counts were used as the primary means to document the responses to questions with nominal variables. The survey utilized questions structured for analysis of both nominal and ordinal data. Chi square tests were used for nominal to nominal variables. Crosstab analysis with chi square tests using the Phi coefficient and Pearson's chi square were used when seeking to identify statistically significant associations for nominal to ordinal and ordinal to ordinal variables. Ordinal data was collected primarily using five-point likert scale questions ( $\alpha$ $=.05$ ). However, questions related to the potential use of CAD (Computer aided drafting), 3D computer modeling, and design $n$ visualization utilized a seven-point likert scale $(\alpha=.05)$ on the assumption that the results would be more conclusive. One sample t-tests were also used to identify statistically significant mean differences, using a neutral test value of 3 for the five-point likert scale questions and a neutral value of 4 for the seven-pint likert scale questions. Additionally, where appropriate, bi-variate correlations $(\alpha=.05)$ were used for further analysis of ordinal to ordinal variables, and one-way analysis of variance (ANOVA) was used to determine if there were any significant between-group associations between nominal and/or demographic variables and variables configured as ordinal data.

The survey was formatted and administered using Snap Version 8 survey software. The software was used to send an e-mail using a database generated from the spreadsheet with faculty e-mail addresses. The e-mail request provided general information about the study and asked the recipient to participate in the study. The e-mail included a link to the survey web site, stored on a dedicated university server, which respondents used to open the survey in their web browser. The software also tracked the respondents in order to send follow-up reminders and also to block respondents from attempting to respond more than one time.

\section{Demographics and findings related to current uses of design technologies.}

Of the 291 requests for participation that were sent, there were 52 valid responses submitted. $53.8 \%(\mathrm{~N}=28)$ were from institutions with architectural engineering programs with an enrollment exceeding 200 students. $11.5 \%(\mathrm{~N}=6)$ were from programs with enrollments between 150 and 200 students, 21.2\% (N=11) were from programs with enrollments between 
100 and 150 students, and $13.4 \%$ (N=7) were from programs with enrollments below 100 students. The demographic data collected indicated that $90.6 \%$ of the respondents were assistant, associate, or full professors. The academic rank of the respondents is documented in the following table:

\begin{tabular}{|l|l|l|}
\hline Table 1: Academic Rank & N & Percentage \\
\hline Assistant Professor & 16 & $30.8 \%$ \\
\hline Associate Professor & 14 & $26.9 \%$ \\
\hline Professor & 17 & $32.7 \%$ \\
\hline Lecturer & 1 & $1.9 \%$ \\
\hline Instructor & 2 & $3.8 \%$ \\
\hline Other/No Response & 2 & $3.8 \%$ \\
\hline
\end{tabular}

The primary academic background of the respondents was somewhat diverse. Faculty with backgrounds in architecture $(28.8 \%, \mathrm{~N}=15)$ and structural engineering $(26.9 \%, \mathrm{~N}=14)$ made up over half of the respondents, followed by architectural engineering $(23.1 \%, \mathrm{~N}=12)$. The academic background of the respondents is documented in the following table:

\begin{tabular}{|l|l|l|}
\hline Table 2: Academic Background & Frequency & Percent \\
\hline Architecture & 15 & $28.8 \%$ \\
\hline Architectural Engineering & 12 & $23.1 \%$ \\
\hline Engineering: Civil & 4 & $7.7 \%$ \\
\hline Engineering: Structural & 14 & $26.9 \%$ \\
\hline Engineering: Electrical/Mechanical & 4 & $7.7 \%$ \\
\hline Construction & 2 & $3.8 \%$ \\
\hline Other & 1 & $1.9 \%$ \\
\hline Total & 52 & 100.0 \\
\hline
\end{tabular}

The primary instructional area of the respondents was also somewhat diverse. While faculty teaching structures represented the largest group $(30.8 \%, \mathrm{~N}=16)$, the respondents identifying their primary instructional areas from the list ranged from two $(3.8 \%)$ for architectural history/theory to eight $(15.4 \%)$ for mechanical/environmental systems. It should be noted that three of the listed categories did not get any valid responses. The primary instructional area reported by the respondents is documented in the following table:

\begin{tabular}{|l|l|l|}
\hline Table 3: Primary Instructional Focus & Frequency & Percent \\
\hline Architectural History and/or Theory & 2 & $3.8 \%$ \\
\hline Structures & 16 & $30.8 \%$ \\
\hline Construction and/or building materials and methods & 4 & $7.7 \%$ \\
\hline Mechanical/Environmental systems & 8 & $15.4 \%$ \\
\hline Architectural Graphics (representation) courses) & 2 & $3.8 \%$ \\
\hline
\end{tabular}




\begin{tabular}{|l|l|l|}
\hline Architectural Design (design foundations) courses and/or firs & 6 & $11.5 \%$ \\
\hline Architectural Design (upper level and/or graduate studio) & 6 & $11.5 \%$ \\
\hline Computer Aided Drafting and/or Design & 3 & $5.8 \%$ \\
\hline Other & 5 & $9.6 \%$ \\
\hline Total & 52 & $100.0 \%$ \\
\hline
\end{tabular}

\section{Current utilization of digital design applications: Software used in architectural engineering curriculums.}

As noted previously, there were two primary queries regarding the specific software applications that were used in the respondent's Architectural Engineering curriculum as well as in the classes they themselves taught. AutoCAD was the application that was reported to be most widely used, with $88.5 \%(\mathrm{~N}=46)$ of the respondents listed it as being utilized in courses in their curriculum. Sketchup software was the next most commonly identified application (38.5\%, $\mathrm{N}=20$ ), followed by Autodesk Architectural Desktop (36.5\%, N=19), Autodesk Revit (30.8\%, $\mathrm{N}=16)$, and Autodesk Viz (25\%, $\mathrm{N}=13)$. The responses relative to the use of the remainder of the applications ranged from $15.4 \%(\mathrm{~N}=8)$ for Form $\mathrm{Z}$, to $0 \%(\mathrm{~N}=0)$ for several of the listed applications. Fifteen (28.8\%) of respondents identified one of the six GSA approved BIM applications as an application utilized in their curriculums while 14 (26.9\%) reported that more than one of the six BIM applications were used.

The second query intended to identify software used in courses by the respondents themselves, found that AutoCAD was the most widely used application $(61.5 \%, \mathrm{~N}=32)$. However, "none" was listed by $26.9 \%$ of the respondents $(\mathrm{N}=14)$. The responses indicated the utilization for the remainder of the applications was to some parallel with the overall curricular use. The data identified Sketchup was utilized by $25 \%(\mathrm{~N}=9)$ of the respondents, followed by Autodesk Architectural Desktop (17.3\%, N=9), Autodesk Revit (11.5\%, N=6), Autodesk Viz $(11.5 \%, \mathrm{~N}=13)$, and FormZ (7.7\%, N=4). Ten (19.2\%) of respondents identified one of the six GSA approved BIM applications as being utilized in their courses and six (11.5\%) indicated they used more than one of the six BIM application in courses that they taught. The responses are in Table 4 and documented in Appendix A. 


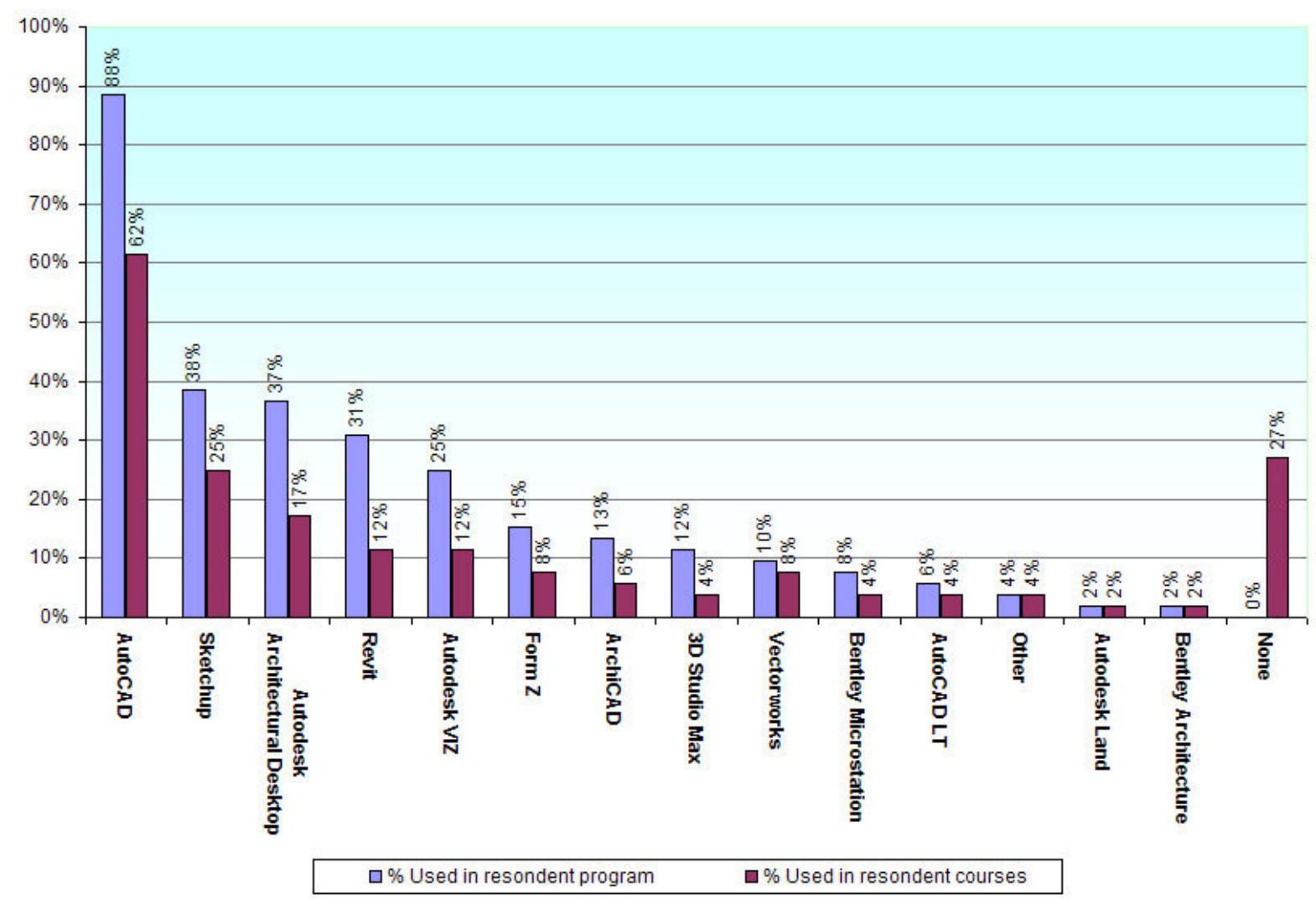

Table 4: Software applications used in Architectural Engineering Curriculums

\section{Current utilization of digital design applications in the specified curriculum content areas:}

As was anticipated, CAD drafting was reported to be the most utilized of the three computing areas. The highest level of reported use $(71.2 \%, \mathrm{~N}=37)$ was in upper level and/or graduate architectural design studios, followed by Architectural Graphics (representation) courses $(65.4 \%, \mathrm{~N}=34)$ and then by architectural design foundations courses $(40.4 \%, \mathrm{~N}=21)$. There was one response of "none" for CAD drafting (1.9\%).

Respondents reported the highest utilization for 3D modeling in design foundations courses $(50 \%, \mathrm{~N}=26)$, with the second highest reported utilization for upper level and/or graduate architectural design studios $(30.6 \%, \mathrm{~N}=16)$. Respondents reported limited use in the other instructional areas reported ranging from $17.3 \%$ for structures $(\mathrm{N}=9)$ to $0 \%(\mathrm{~N}=0)$ for architectural history/theory. It should be noted that 7 respondents $(13.5 \%)$ indicated 3D modeling was not used in their curriculum.

The utilization of design visualization was highest in the design studios, with $46.2 \%$ $(\mathrm{N}=24)$ of the respondents listing upper level and/or graduate architectural design studios as using design visualization. However, the second highest response for design visualization was "none" $(26.9 \%, \mathrm{~N}=14) .25 \%(\mathrm{~N}=13)$ responded that design visualization was used in Architectural Graphics (representation) courses and 19.2\% ( $\mathrm{N}=10)$ reported its use in Architectural Design (design foundations) courses. As with 3D modeling, 0\% ( $\mathrm{N}=0)$ reported 
that design visualization was used in architectural history/theory courses. The responses to these questions are documented in Appendix B.

\section{Current utilization of Computer Aided Drafting (2D), Computer Aided Design (3D computer modeling), and Design Visualization in design courses:}

As noted in the previous section, design courses were identified as the content areas were most students that utilized CAD drafting, 3D modeling, as well as design visualization.

Therefore, the more specific questions relating to the use of these technologies in design studio were intended to provide greater insight into how computing tools were utilized in design coursework. The responses indicated that most architectural engineering curriculums utilize CAD drafting and 3D modeling in both the upper and lower level design courses. CAD drafting was reported to be primarily utilized in upper level design courses by $50 \%(\mathrm{~N}=26)$ of the respondents, followed by $28.8 \%(\mathrm{~N}=15)$ for only upper level design studios and $7.7 \%(\mathrm{~N}=4)$ for lower level design studios only. $7.7 \%(\mathrm{~N}=4)$ of respondents indicated that CAD drafting was not used by most students in design courses in their program. Similarly, 3D computer modeling was reported to be primarily utilized in upper level design courses by $44.2 \%(\mathrm{~N}=23)$ of the respondents, followed by $28.8 \%(\mathrm{~N}=15)$ for only upper level design studios. Only $3.8 \%(\mathrm{~N}=2)$ of respondents indicated that 3D computer modeling was used primarily in lower level design studios while $17.3 \%(\mathrm{~N}=9)$ indicated it was not used by most students in design courses in their program. Responses to the question asking respondents to indicate the design courses where design visualization was most utilized by students found that $36.5 \%(\mathrm{~N}=19)$ of respondents indicated that design visualization was utilized most in upper level design courses and $28.8 \%$ $(\mathrm{N}=15)$ indicated that it was used in both upper and lower design courses. However, 26.9\% $(\mathrm{N}=14)$ reported that design visualization was not used by students at all in their programs. These responses are summarized in table 5 and documented in Appendix C.

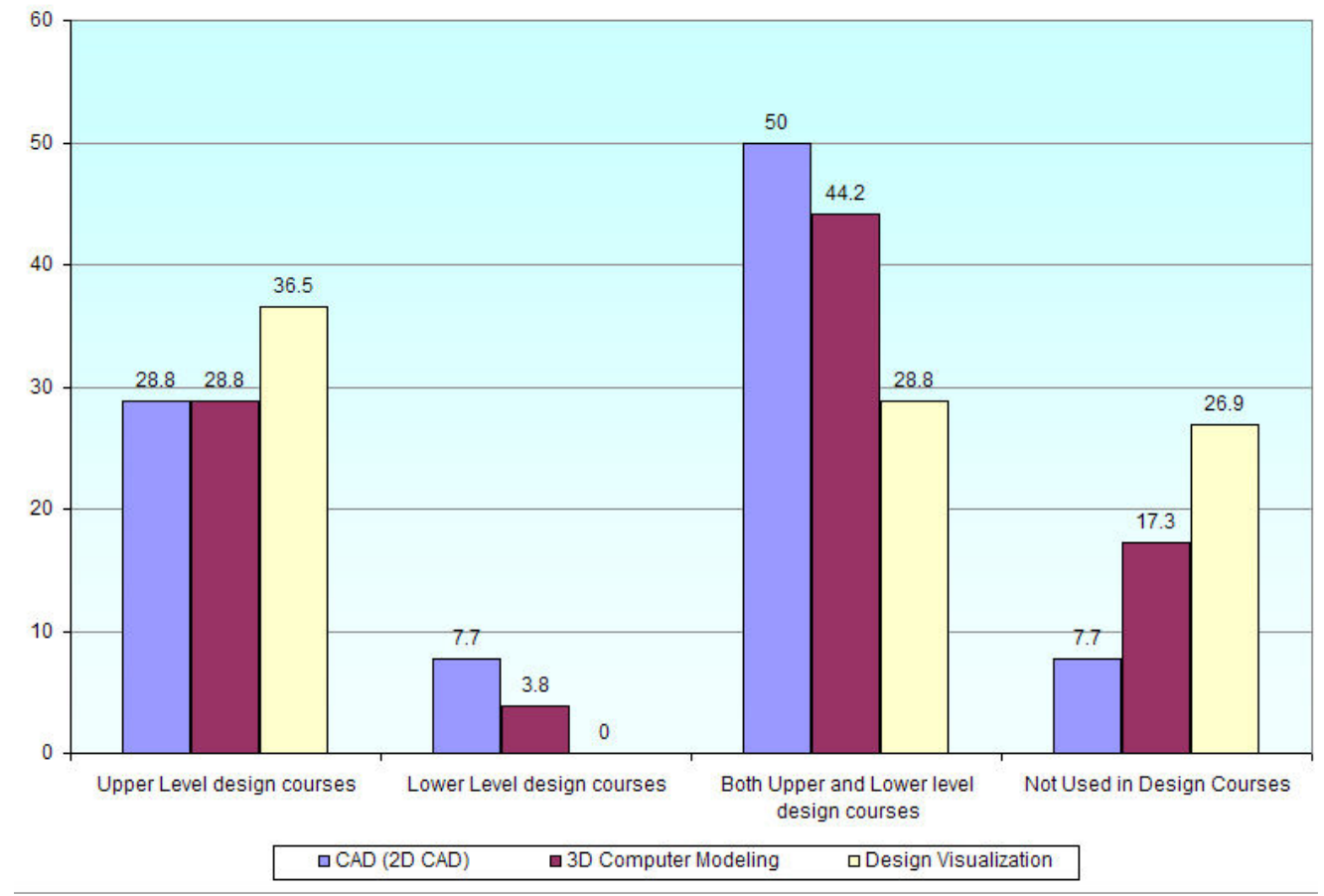

Table 5: Use of CAD, computer modeling, and design visualization in design studios 


\section{Current use of computer aided fabrication.}

The data collected indicated use of computer aided fabrication was somewhat limited. Only 6 respondents $(11.5 \%)$ indicated that it was used in their curriculums, while $34(65.4 \%)$ indicated it was not and $11(21.6 \%)$ indicated they did not know. When considering specific technologies, 2 respondents (3.9\%) reported the use of CAM (Computer Aided Manufacturing), while $44(85.6 \%)$ indicated it was not used and $5(9.6 \%)$ indicated they did not know. The most commonly used equipment was a Rapid Prototype 3D Printer $(\mathrm{N}=3)$. One respondent responded that a laser cutter was used, and another reported "other." The survey also asked respondents to rate the extent to which they felt skill development with computer aided fabrication was a priority for professional preparation. Only one respondent indicated "very high priority." In contrast, $20(37.5 \%)$ responded with either "low priority" or "very low priority." These responses are documented in table 6.

$\begin{array}{lll}\text { Table 6: Current use of Computer Aided Fabrication } & \mathrm{N}=52 \\ \text { Very High Priority } & 1 & 1.9 \% \\ \text { High Priority } & 14 & 26.9 \% \\ \text { Neutral } & 14 & 26.9 \% \\ \text { Low Priority } & 9 & 17.3 \% \\ \text { Very Low Priority } & 11 & 21.2 \% \\ \text { No response } & 3 & 5.8 \%\end{array}$

\section{The influence of other factors on current use of digital design technologies.}

In order to gain additional insight into the data related to the current uses of digital design technologies in architectural engineering curriculums, statistical analysis was used to determine the degree to which the responses were associated with instructional focus and enrollment size. Data compiled from the responses to the questions related to instructional focus and data relative to current uses of digital design technologies was nominal, which restricted analysis beyond frequency counts and Chi-Square tests. Chi square analysis between primary instructional focus and current use of CAD drafting did find statistically significant associations for all listed instructional areas except for Design Foundations. Similarly, Chi square analysis between primary instructional focus and current use of 3D modeling and design visualization found statistically significant associations for all listed instructional areas except for Architectural Graphics for 3D modeling and design studio for design visualization. However, the relatively low number of responses listed for several of the individual instructional areas limit the conclusions that can be drawn from this analysis. Additionally, it should be noted that while the chi square test can be used to identify significant associations between nominal variables, the tests do not differentiate between variable categories. Therefore, the tests do not identify a specific content area but rather consider the content area variable as a whole.

Data compiled from the responses to the questions related to enrollment and data relative to current uses of digital design technologies was both ordinal (enrollment) and nominal (content 
area). Crosstab analysis using Phi and Pearsons chi-square did reveal a significant association $(\mathrm{p}=.026)$ between enrollment and the use of CAD in architectural graphics courses and design studio ( $\mathrm{p}=.033$ ), indicating that the use of CAD in these content areas was somewhat related to program size. Crosstab analysis revealed a significant association between enrollment and the use of 3D computer modeling in design studio $(\mathrm{p}=.045)$ and it should be noted that, while not statistically significant, the tests for association between the enrollment and the use of 3D computer modeling in structures $(\mathrm{p}=.051)$ were relatively close to the .95 confidence interval used in testing. Tests for association between the enrollment and the use of design visualization in the course content areas yielded statistically significant results for structures $(p=.027)$.

\section{Findings related to Building Information modeling in architectural engineering curriculums.}

As noted previously, only 15 (28.8\%) of respondents identified one or more of the six GSA approved BIM applications as an application utilized in their curriculum. Respondents were also asked indicate their level of awareness of building information modeling using predefined likert-scale response ranging from "very" aware to "not at all" aware. However, despite the low number of respondents indicating they used a BIM application, 33 respondents $(64.7 \%)$ indicated they were either "very" aware or "moderately" aware and/or familiar with the concepts of building information modeling. Therefore, it can be assumed that responses to questions related to Building Information Modeling, and associated statistical analysis, may provide insight into the status of BIM in architectural engineering curriculums.

When asked to document the BIM features that were utilized, $17(32.7 \%)$ responded "don't know" which would be anticipated since $35.3 \%$ of the responded had provided a rating of "low" or "none" for their familiarity/awareness with the concept of building information modeling. The most commonly identified operations and features were Visualization (rendering) $(\mathrm{N}=17,32.7 \%)$ and generation of $2 \mathrm{D}$ documentation from $3 \mathrm{D}$ geometry $(\mathrm{N}=13,25 \%)$. The results of all responses are listed in the table below.

\begin{tabular}{|l|l|l|}
\hline Table 6: BIM: Commonly utilized features/operations & $\mathrm{N}$ & $\begin{array}{l}\% \text { of total } \\
\text { respondents }\end{array}$ \\
\hline Mass modeling & 11 & $21.2 \%$ \\
\hline styles/parametric modeling & 9 & $17.3 \%$ \\
\hline generation of 2D documentation from 3D geometry & 13 & $25.0 \%$ \\
\hline Inter-operation/file exchange with other BIM applications & 3 & $5.8 \%$ \\
\hline $\begin{array}{l}\text { Integration of extended data (i.e.: notes, schedules, specifications, } \\
\text { etc) with model geometry }\end{array}$ & 8 & $15.4 \%$ \\
\hline Visualization (rendering, etc.) & 17 & $32.7 \%$ \\
\hline Project management/coordination & 6 & $11.5 \%$ \\
\hline Structural design features/tools/libraries & 4 & $7.7 \%$ \\
\hline Don't Know & 17 & $32.7 \%$ \\
\hline
\end{tabular}

Given the demographics of the respondents, the limited use of certain features found in building information modeling applications is somewhat surprising. For example, it would be 
anticipated that since faculty identifying structures as their primary instructional focus made up over $30 \%$ of the respondents, the structural design features/tools/libraries were ranked among the least utilized. This may be attributed in part to the availability of specialized structural design software that faculty in this content feel may be more effective for teaching structural design concepts. However, the respondents indicated that generation of $2 \mathrm{D}$ documentation from $3 \mathrm{D}$ geometry, a key operation in model-centric BIM applications, was the second most utilized feature $(\mathrm{N}=13,25 \%)$, which suggested that many faculty using the building information modeling applications were utilizing advanced features related specifically to design and documentation productivity rather than just the design visualization tools that are common in these software packages. However, the data related to the extent to which faculty felt content on building information modeling was covered in their curriculum revealed that $35.5 \%(\mathrm{~N}=16)$ gave a response of "very high" or "moderate" while 62.2\% ( $\mathrm{N}=28)$ gave a response of "minimal" or "not at all". Therefore, the limited use of advanced BIM features is consistent with the ratings for the extent such content is covered.

In order to determine faculty perceptions of the importance of building information modeling course content in architectural engineering curriculums, the survey asked respondents to indicate the extent to which the operation and use of building information modeling software was covered in their curriculums. The question used likert-scale responses which ranged from "very high, very in-depth" to "not covered at all." For faculty not familiar with building information modeling, a response of "don't know" was also provided in order to exclude these responses from data analysis. The survey also asked the respondents to indicate the extent to which developing student skills with Building Information Modeling operations should be a priority in preparing students for professional practice as an architectural engineer. The data was collected using a five-point likert scale question with responses of "very high priority," "high priority," "neutral," "low priority," and "very low priority." Based on the premise that computer aided design (3D computer modeling), distinguished from computer aided drafting, and design visualization, are two relevant operational sub-sets which are facilitated by building information modeling software, the survey used the same likert-scale rankings to collect data on the extent to which developing student skills with 3D computer modeling and design visualization operations should be a priority in preparing students for professional practice as an architectural engineer.

In order to provide an overview of the data collected, one sample t-tests $(\alpha=.05$, test value $=3$ ) were used to analyze the responses to the five-point likert scale questions relating to the extent to which the operation of BIM software was covered as well as the ratings for the questions documenting the perceived priority for skill development with Building Information Modeling, 3D computer modeling, and design visualization. The t-test for the question relating to the extent to which building information modeling software is covered yielded a statistically significant positive mean difference. However, t-tests on the priority ratings for all three skill areas were found to have statistically significant negative mean differences. Interestingly, analysis using bi-variate correlation $(\alpha=.05)$ found statistically significant positive correlations between the level of familiarity/awareness of the concept of BIM and the ratings for the priority of skill development with BIM ( $\mathrm{p}=.001)$, 3D computer modeling $(\mathrm{p}=.003)$, and design visualization $(\mathrm{p}=.016)$. The ratings for the extent to which the operation of BIM software was covered and the ratings for the priority of skill development with BIM $(\mathrm{p}=.014)$ were also found to be statistically significant. Additionally, bi-variate correlation tests revealed several key 
statistically significant relationships between these variables. These tests revealed a positive correlation between the ratings for the priority assigned to skill development with building information modeling and skill development with 3D modeling $(\mathrm{p}=.000)$, skill development with design visualization $(\mathrm{p}=.000)$, awareness of building information operations/concepts $(\mathrm{p}=.001)$, and the extent to which building information content is covered in courses (.014).

These results suggested even though the respondents generally did not place a high priority on the three specified skill areas in terms of preparation for professional practice, which would have, this was not necessarily the case with those faculty familiar with BIM software and concepts. Rather, the data suggested that as familiarity increased, the priority given to the three skill areas also increased. This is also consistent with the positive correlation between the ratings for the extent to which the operation of BIM software was covered and the ratings for the priority of skill development with BIM, since higher ratings for the extent BIM is covered correlated with priority of BIM skill development.

Analysis to determine the extent to which these results were associated with factors such as related to the respondent's academic background, primary instructional areas, and their use of one or more of the listed building information modelers in their coursework yielded limited results. When considering primary instructional area, the data indicated that there was an association between this variable and the variables related to skill development priority. Chi square test found significant associations between primary instructional area and priority for skill development with design visualization $(=.023)$ as well as priority for skill development with building information modeling $(\mathrm{p}=.004)$. A significant association was also found between primary instructional area and familiarity with BIM concepts $(\mathrm{p}=.029)$. This data indicates that primary instructional area is to some extent related to the priority faculty place on skill development related to BIM, 3D computer modeling, and design visualization. When considering program enrollment as a variable, no significant associations were found between enrollment and any of the skill development variables. Similarly, bi-variate correlation tests found no significant correlations between program enrollment and the skill development variables.

Interestingly, correlation tests between the priority ratings for computer-aided fabrication and the priority ratings for skill development with building information modeling, familiarity/awareness of BIM concepts, computer modeling, and design visualization indicated several strong relationships. There were positive correlations between computer aided fabrication and skill development with computer modeling $(\mathrm{p}=.007)$, design visualization $(\mathrm{p}=$ $.001)$, and most importantly building information modeling $(\mathrm{p}=.000)$. All three correlations, significant at $\alpha=.01$, suggest that faculty that feel that BIM skill development is a priority also feel that fabrication skill development is a priority as well.

\section{Content areas and the potential for integrating Computer Aided Drafting, 3D Computer modeling, and Design Visualization skill development.}

Statistical analysis of the responses related to the extent to which faculty perceived the specified curricular areas could be potentially utilized for skill development was found to be relatively consistent. One sample t-tests on the responses to the seven-point likert scale 
questions, using a test value 4 for neutral, yielded statistically significant results for the potential for integrating Computer Aided Drafting skills for all eight specified curriculum areas. Architectural Design (capstone and/or advanced studio courses) yielded the highest positive mean difference $(\mathrm{M}=1.82, \mathrm{p}=.000)$. However, the mean difference for the responses for architectural history and/or theory was negative $(\mathrm{M}=-1.43, \mathrm{p}=.000)$, which indicated that faculty did not perceive this content area would be effective for CAD skill development. Similarly, one sample t-tests on the responses to the seven-point likert scale questions, using a test value 4 for neutral, yielded statistically significant results for the potential for integrating Computer Modeling skills for all eight specified curriculum areas. Architectural Design (capstone and/or advanced studio courses) yielded the highest positive mean difference $(\mathrm{M}=$ $2.00, \mathrm{p}=.000$ ), indicating this content area was perceived to have somewhat stronger potential for 3D skill development than for computer aided drafting. As with the ratings for potential integration of computer aided drafting, the mean difference for the responses for architectural history and/or theory was negative $(\mathrm{M}=-1.76, \mathrm{p}=.000)$, which indicated that faculty did not perceive this content area would be effective for 3D computer modeling skill development. When considering the analysis of the responses related to the potential for design visualization skill development, the results were less consistent. Analysis yielded statistically significant results for the potential for integrating design visualization skill development for six of the eight specified curriculum areas. Ratings for site design and construction/materials and methods did not yield statistically significant responses. However, as in the prior analysis, the ratings for architectural design produced the highest positive mean difference $\left(\mathrm{M}=1.82, \mathrm{p}_{-}=.000\right)$, and the ratings for architectural history and/or theory yielded a significant negative mean difference (M $=-1.00, p_{-}=.002$ ).

Results of analysis of the ratings for the specified content areas in relation to the respondent's primary instructional areas and their use of one or more of the listed building information modelers in their coursework yielded limited results. Chi-square tests found no significant associations between the ratings for potential integration of 2D CAD skills and primary instructional focus. However, the data did yield a limited number of significant relationships between primary instructional focus and the potential for content areas to be used for skill development with 3D computer modeling. Crosstab chi-square analysis using the Phi coefficient found significant relationships between ratings the potential of the specified content areas primary instructional focus for mechanical/environmental $(p=.050)$, construction and/or materials and methods $(p=.036)$, and architectural design (foundation courses) $(p=.048)$. Similarly, significant relationships were found between primary instructional focus and the potential for content areas to be used for skill development with skills in design visualization. Crosstab chi-square analysis using the Phi coefficient found significant relationships between ratings for the potential of the specified content areas and primary instructional focus in mechanical/environmental ( $\mathrm{p}=.010)$, construction and/or materials and methods $(\mathrm{p}=.016)$, and architectural design (foundation courses) $(\mathrm{p}=.044)$.

\section{Summary}

The purpose of this study was to document the current utilization of Computer Aided Drafting (two dimensional CAD), Computer Aided Design and modeling (three dimensional CAD), design visualization (computer rendering, animation, and representation), and building 
information modeling (BIM) in architectural engineering curriculums, as well as the potential for these technologies to be integrated into various course-content areas. The study also sought to document the specific software used in architectural engineering programs for purposes of 2D and 3D design and for digital representations. Additionally, the study sought to provide insight into whether faculty perceived skill development with Building Information Modeling, 3D computer modeling, design visualization, and computer aided fabrication should be a priority in professional education of architectural engineering students. It should be noted that this study did not attempt to utilize a random sample and that no attempt was made to collect data that could be used to determine the extent to which all four-year ABET accredited architectural engineering programs are represented in the responses. Therefore, the degree to which generalizations and conclusions drawn are applicable to all architectural engineering faculty and programs is limited.

While the data suggest that most architectural engineering programs are utilizing a wide range of digital design applications, including building information modeling applications in many programs, the extent to which the use of these technologies has been integrated in coursework across most curriculums is limited. It is possible to conclude that, in terms of the respondents to this study, many faculty see potential for greater integration of skill development in several areas of their curriculum. Since many of the respondents in this study indicated that at least some of the specified curricular areas have potential for developing student skills with more advanced computing operations, it could be concluded that this broader use of digital design technologies could also be used to support skill development associated with Building Information Modeling.

However, given the potential impact Building Information Modeling will have on the AEC industry, the limited integration of many advanced BIM features in architectural engineering curriculums suggests that there may be a disconnect between current use of these technologies in education and developing trends in professional practice. As an example, the minimal use of computer aided fabrication indicates that the expanding role of integrated design and manufacturing in practice is not being equally embraced in architectural engineering curriculums. While it could be argued that the extent to which the use of fabrication in practice has not grown to a level where it is necessary to introduce this technology into the architectural engineering coursework, it can be anticipated that the increasing adoption of Building Information Modeling tools in practice will also increase the use of advanced technologies such as fabrication. The strong association between the priority ratings for skill development with BIM and skill development with fabrication suggests that faculty using BIM in architectural engineering programs may be more aware of trends in professional practice and the potential for using these technologies to develop student skills to meet the future the needs of the design and engineering professions.

More importantly, the increasing adoption of digital design applications not traditionally utilized in architectural practice also suggests that architectural engineering curriculums may need to reconsider the role of fabrication. Catia, primarily developed for aviation design, and Pro-engineer, widely used in manufacturing and automotive industries, are optimized designdevelopment environments and provide integrated support for fabrication [4]. Rhinoceros, a nurbs-based modeler commonly referred to as Rhino, is being adopted for its ease of use as well as it's capability to produce "watertight" geometry required for manufacturing, fabrication, and 
proto-typing [14]. Many such features can be easily utilized even in early design phases. For example, Rhino provides an UnrollSurf command that enables a designer to select a surface and, at any point in the design process, determine if the geometry is "developable". A developable surface is a surface that can be "flattened" for a variety of manufacturing and fabrication processes [4]. Rhino, Catia, and to some extent Pro-engineer, are increasingly being utilized in architectural design environments, and the utilization of these technologies suggest that fabrication will emerge as an important aspect of architectural practice and therefore should be prioritized in design curriculums.

Conclusions related to the limited use of BIM features must consider two key findings. First, the data reveal that, in general, faculty responding to this survey did not place a high priority on skill development with BIM, and second, the faculty responding to this survey reported that, even though BIM application were, architectural engineering programs in general are not allocating course content to skill development with BIM. While it is not possible from the data to draw conclusions regarding the extent to which these two key findings correlate, the rapid adoption of BIM applications in the profession, along with the associated paradigm shift in design processes and project delivery, suggest that educators should give serious consideration to curricular changes in order to adequately prepare graduates for professional practice.

\section{References}

[1] Kilkelly, M. (2000). Off the Page: Object Oriented Construction Drawings. In The ACADIA Conference Proceedings: Eternity, Infinity, and Virtuality. Washington DC: 147 - 151.

[2] Ethier, S. \& Ethier, C. (2000). Instant AutoCAD architectural desktop. New York: Prentice Hall.

[3] Davis, Dianne. (2003). Davis, Dianne. (2003). Available online at http://www.aia.org/tap_a_0903bim

[4] Schodek, D, Bechthold, M., Griggs, K., and Kao, K, Steinberg, M. (2005). Digital design and manufacturing: CAD/CAM applications in architecture and design. New York: Wiley \& Sons.

[5] Lev, Sara. Computing buildings: Architecture at the crossroads. Available online at http://www.stanford.edu/group/STS/techne/Fall2002/lev.html

[6] Roberts (2004). http://www.aia.org/pod_kamhagan\&sSelect=content

[7] AIA Podnet. GSA mandates on Building Information Modeling. Available on-line at http://www.aia.org/pod_kamhagan\&sSelect=content

[8] General Services Administration (2006). GSA's National 3D-4D-BIM program. Available on-line at: http://www.gsa.gov/gsa/cm_attachments/GSA_DOCUMENT/Flyer_10_30_R2CU43_0Z5RDZ-i34K-pR.pdf

[9] Kirby, L. (2006). 1-2-3 Revit: Small firms take on BIM. In Cadalyst. http://aec.cadalyst.com/aec/article/articleDetail.jsp?id=389886

[10] Guidera, S. (June 24, 2003) Exploring the architecture of structure: Integrating structures into design studio using object-oriented CAD. 2003 Annual Conference of the American Society for Engineering Education. Nashville, TN.

[11] Rundell, R. (2004). Ensure your success in your transition to BIM. In Cadalyst. http://aec.cadalyst.com/aec/article/articleDetail.jsp?id=134864

[12] http://www.abet.org/accredited_programs.shtml

[13] GSA Presentation on 3D-4D Building Information Modeling Initiative. Presented at Getting Real: Design Ethos Now. $94^{\text {th }}$ ACSA annual meeting. Salt Lake City, UT

[14] Robert McNeel \& Associates (2004). STL file repair in Rhinoceros. Available on-line at http://download.mcneel.com/download.asp?id=STLRepair 


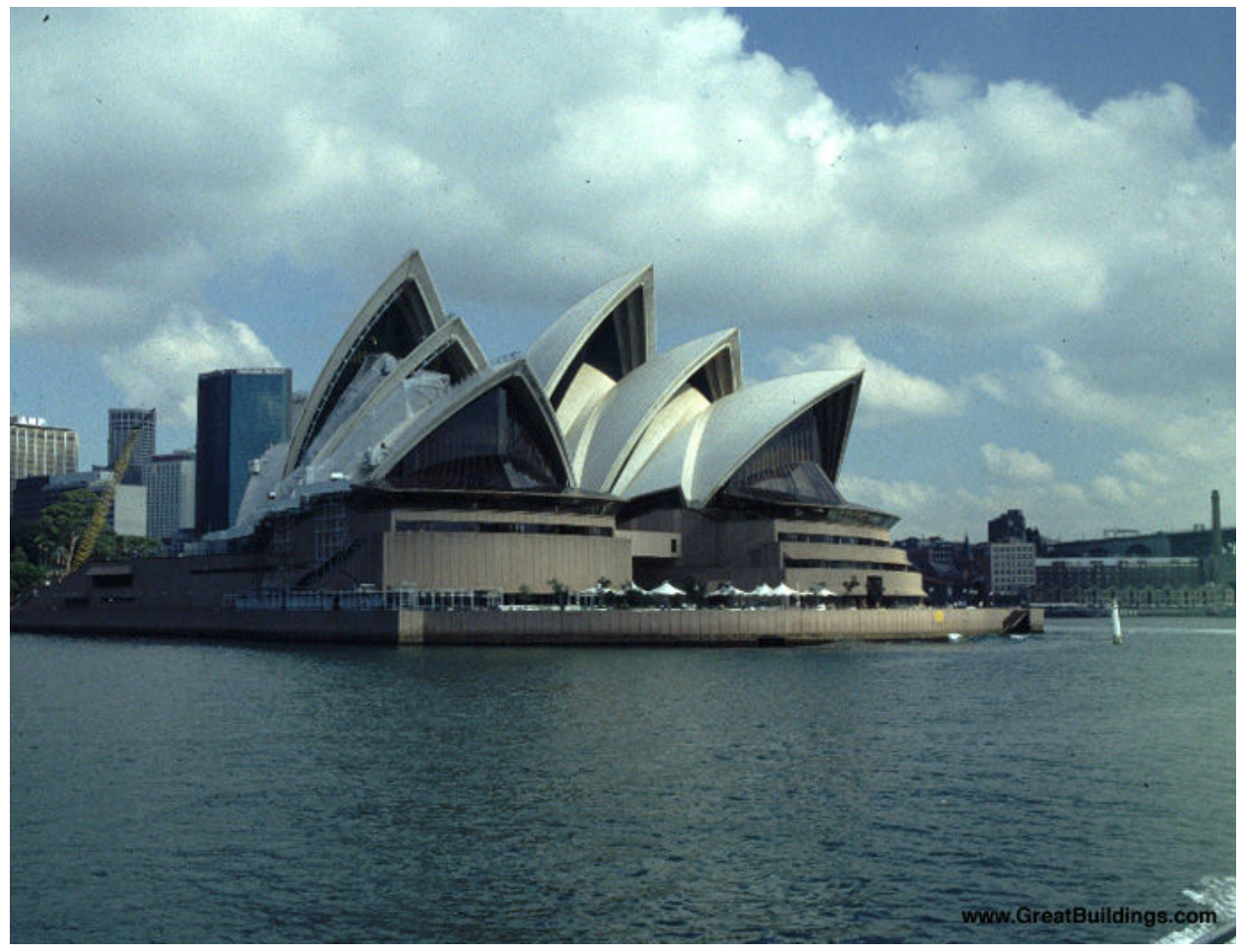

Figure 1. Sydney Opera House, Sydney, Australia.

Jorn Utzom, Architect

Ove Arup and Partners, Engineers

http://www.greatbuildings.com/buildings/Sydney_Opera.html

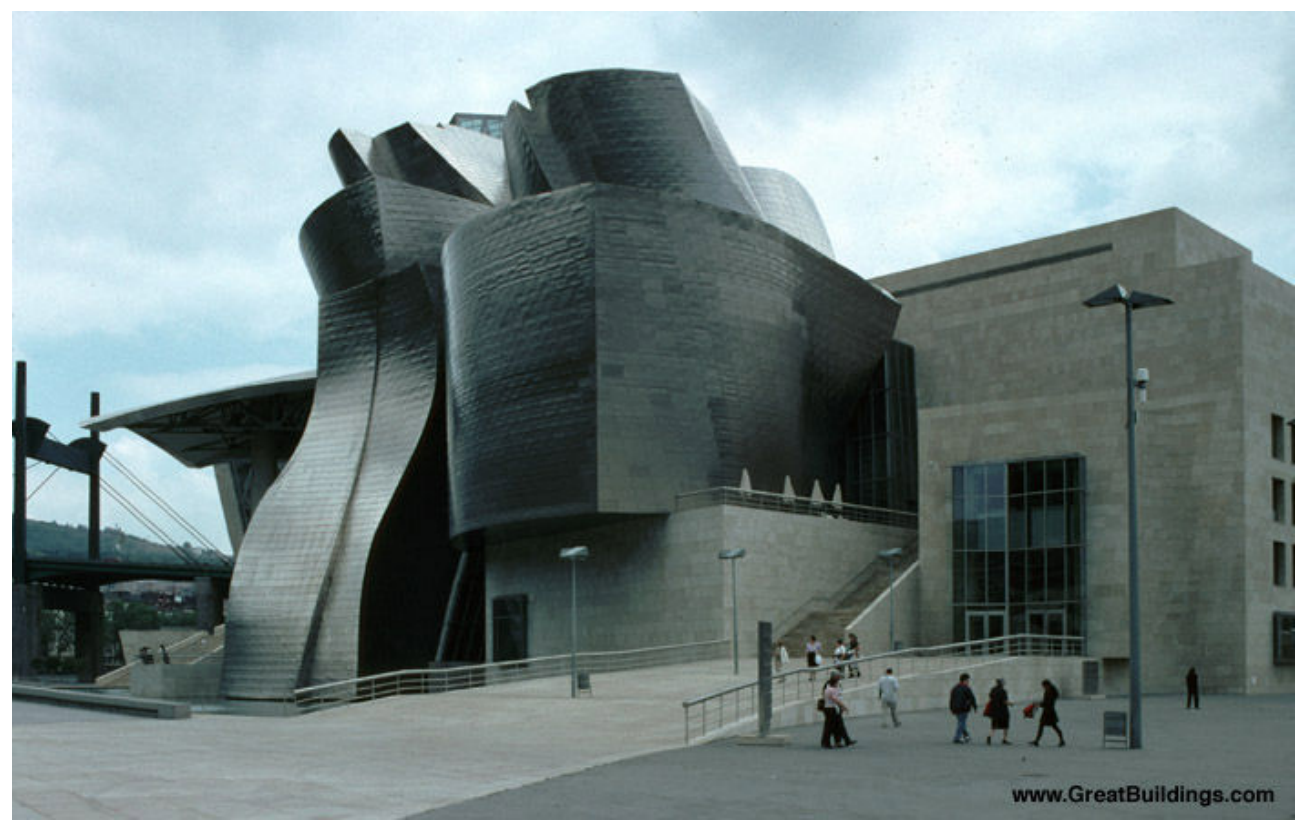

Figure 2. Guggenheim Bilboa in Barcelona, Spain.

Frank Gehry, Architect

http://www.greatbuildings.com/buildings/Guggenheim_Bilbao.html 
Appendix A: Software applications utilized

\begin{tabular}{|c|c|c|c|c|}
\hline APPLICATION & 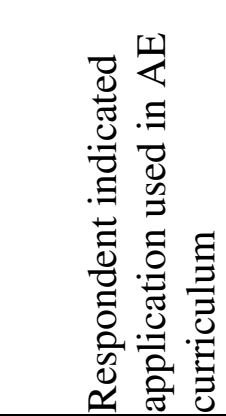 & 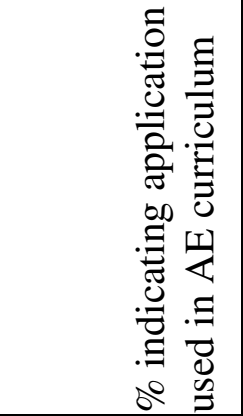 & 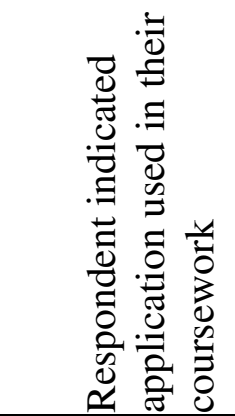 & \\
\hline AutoCAD & 46 & $88.5 \%$ & 32 & $61.5 \%$ \\
\hline Sketchup & 20 & $38.5 \%$ & 13 & $25.0 \%$ \\
\hline $\begin{array}{l}\text { Autodesk Architectural } \\
\text { Desktop }\end{array}$ & 19 & $36.5 \%$ & 9 & $17.3 \%$ \\
\hline Revit & 16 & $30.8 \%$ & 6 & $11.5 \%$ \\
\hline Autodesk VIZ & 13 & $25.0 \%$ & 6 & $11.5 \%$ \\
\hline Form Z & 8 & $15.4 \%$ & 4 & $7.7 \%$ \\
\hline ArchiCAD & 7 & $13.5 \%$ & 3 & $5.8 \%$ \\
\hline 3D Studio Max & 6 & $11.5 \%$ & 2 & $3.8 \%$ \\
\hline Vectorworks & 5 & $9.6 \%$ & & $0.0 \%$ \\
\hline Bentley Microstation & 4 & $7.7 \%$ & 2 & $3.8 \%$ \\
\hline AutoCAD LT & 3 & $5.8 \%$ & 2 & $3.8 \%$ \\
\hline Don't Know & 3 & $5.8 \%$ & 14 & $26.9 \%$ \\
\hline Other & 2 & $3.8 \%$ & 4 & $7.7 \%$ \\
\hline Autodesk Land & 1 & $1.9 \%$ & 1 & $1.9 \%$ \\
\hline Bentley Architecture & 1 & $1.9 \%$ & 1 & $1.9 \%$ \\
\hline TurboCAD & 1 & $1.9 \%$ & 0 & $0.0 \%$ \\
\hline Catia (Gehry Technologies) & 0 & $0.0 \%$ & 0 & $0.0 \%$ \\
\hline Maya & 0 & $0.0 \%$ & 0 & $0.0 \%$ \\
\hline Rhino & 0 & $0.0 \%$ & 0 & $0.0 \%$ \\
\hline None & 0 & $0.0 \%$ & 2 & $3.8 \%$ \\
\hline
\end{tabular}


Appendix B Appendix B: Use of CAD, 3D modeling, and design visualization in architectural engineering instructional content areas

\begin{tabular}{|l|l|l|}
\hline Current curricular use of CAD Drafting \\
\hline Architectural History and/or Theory & 1 & $1.9 \%$ \\
\hline Structures & 16 & $30.8 \%$ \\
\hline Construction and/or building materials and methods & 16 & $30.8 \%$ \\
\hline Mechanical/Environmental systems & 16 & $30.8 \%$ \\
\hline Architectural Graphics (representation) courses) & 34 & $65.4 \%$ \\
\hline Architectural Design (design foundations) courses and/or firs & 21 & $40.4 \%$ \\
\hline Architectural Design (upper level and/or graduate design & 37 & $71.2 \%$ \\
\hline Other & 6 & $11.5 \%$ \\
\hline None & 1 & $1.9 \%$ \\
\hline
\end{tabular}

\section{Current curricular use of 3D modeling}

Architectural History and/or Theory

$0.0 \%$

Structures

$9 \quad 17.3 \%$

Construction and/or building materials and methods

$3 \quad 5.8 \%$

Mechanical/Environmental systems

$3 \quad 5.8 \%$

Architectural Graphics (representation) courses)

$6 \quad 11.5 \%$

Architectural Design (design foundations) courses and/or firs $\quad 26 \quad 50.0 \%$

Architectural Design (upper level and/or graduate design

studios

Other

$16 \quad 30.8 \%$

None

$3 \quad 5.8 \%$

$7 \quad 13.5 \%$

\section{Current curricular use of DV}

$\begin{array}{lll}\text { Architectural History and/or Theory } & 0 & 0.0 \%\end{array}$

Structures

$5 \quad 9.6 \%$

Construction and/or building materials and methods

$1 \quad 1.9 \%$

Mechanical/Environmental systems

$3 \quad 5.8 \%$

Architectural Graphics (representation) courses)

$13 \quad 25.0 \%$

Architectural Design (design foundations) courses and/or firs $10 \quad 19.2 \%$

Architectural Design (upper level and/or graduate design

studios

$24 \quad 46.2 \%$

Other

$3 \quad 5.8 \%$

None

$14 \quad 26.9 \%$


Appendix C.

\begin{tabular}{|ll|l|l|l|l|}
\hline $\begin{array}{l}\text { DESIGN content area: } \\
\text { Use of CAD Drafting }\end{array}$ & Frequency & Percent & Valid Percent & $\begin{array}{l}\text { Cumulative } \\
\text { Percent }\end{array}$ \\
\hline Valid & $\begin{array}{l}\text { Upper Level design } \\
\text { courses }\end{array}$ & 15 & 28.8 & 30.6 & 30.6 \\
& $\begin{array}{l}\text { Lower Level design } \\
\text { courses (design } \\
\text { foundation courses) } \\
\text { Both Upper and Lower } \\
\text { level design courses } \\
\text { Not used in design } \\
\text { courses in our program by } \\
\text { most students } \\
\text { Total }\end{array}$ & 4 & 7.7 & 8.2 & 38.8 \\
System & 49 & 50.0 & 53.1 & 100.0 \\
Missing & 3 & 7.7 & 8.2 & \\
Total & 52 & 5.8 & 100.0 & \\
\hline
\end{tabular}

\begin{tabular}{|c|c|c|c|c|c|}
\hline \multicolumn{2}{|c|}{$\begin{array}{l}\text { DESIGN content area: Use of 3D } \\
\text { computer modeling }\end{array}$} & \multirow{2}{*}{$\begin{array}{l}\text { Frequency } \\
15\end{array}$} & \multirow{2}{*}{$\begin{array}{l}\text { Percent } \\
28.8\end{array}$} & \multirow{2}{*}{$\begin{array}{l}\text { Valid Percent } \\
30.6\end{array}$} & \multirow{2}{*}{$\begin{array}{l}\text { Cumulative } \\
\text { Percent } \\
30.6\end{array}$} \\
\hline Valid & $\begin{array}{l}\text { Upper Level design } \\
\text { courses }\end{array}$ & & & & \\
\hline & $\begin{array}{l}\text { Lower Level design } \\
\text { courses }\end{array}$ & 2 & 3.8 & 4.1 & 34.7 \\
\hline & $\begin{array}{l}\text { Both Upper and Lower } \\
\text { level design courses }\end{array}$ & 23 & 44.2 & 46.9 & 81.6 \\
\hline & $\begin{array}{l}\text { Not used in design } \\
\text { courses in our program by } \\
\text { most students }\end{array}$ & 9 & 17.3 & 18.4 & 100.0 \\
\hline & Total & 49 & 94.2 & 100.0 & \\
\hline Missing & System & 3 & 5.8 & & \\
\hline Total & & 52 & 100.0 & & \\
\hline
\end{tabular}

\begin{tabular}{|c|c|c|c|c|c|}
\hline \multicolumn{2}{|c|}{$\begin{array}{l}\text { DESIGN content area: Use of Design } \\
\text { Visualization }\end{array}$} & Frequency & Percent & Valid Percent & $\begin{array}{l}\text { Cumulative } \\
\text { Percent }\end{array}$ \\
\hline \multirow[t]{4}{*}{ Valid } & $\begin{array}{l}\text { Upper Level design } \\
\text { courses }\end{array}$ & 19 & 36.5 & 39.6 & 39.6 \\
\hline & $\begin{array}{l}\text { Both Upper and Lower } \\
\text { level design courses }\end{array}$ & 15 & 28.8 & 31.3 & 70.8 \\
\hline & $\begin{array}{l}\text { Not used in design } \\
\text { courses in our program by } \\
\text { most students }\end{array}$ & 14 & 26.9 & 29.2 & 100.0 \\
\hline & Total & 48 & 92.3 & 100.0 & \\
\hline Missing & System & 4 & 7.7 & & \\
\hline Total & & 52 & 100.0 & & \\
\hline
\end{tabular}

